\title{
Pengembangan Kreativitas Dalam Pembelajaran Matematika Melalui Model Brain Based Learning Siswa Sekolah Dasar
}

\author{
Adi Apriadi Adiansha ${ }^{1)^{*}}$, Husnul Khatimah $^{1)}$, Asriyadin ${ }^{1)}$ \\ ${ }^{1)}$ STKIP Taman Siswa Bima \\ *adiapriadiadiansyah@gmail.com
}

Abstrak: Pengembangan kreativitas menjadi hal yang terpenting dalam proses pembelajaran, agar siswa belajar bagaimana menemukan jawaban yang inovatif dan belajar bagaimana melihat suatu pemecahan masalah dari berbagai sudut pandang serta dapat menyelesaikan pemecahan masalah dengan kreativitas. Tujuan penelitian yaitu untuk mengetahui pengembangan kreativitas dalam pembelajaran matematika melalui model Brain Based Learning pada siswa SD. Jenis penelitian yang digunakan metode ekperimen murni, dimana kelas Eksperimen yaitu SDN Nggembe dan Kelas Kontrol yaitu SDN Rada yang ada di Kecamatan Bolo Kabupaten Bima. Instrumen yang digunakan menggunakan kreativitas matematika yang telah dikembangkan dari penelitian sebelumnya sesuai dengan indikator-indikator pada kelancaran, keluwesan, keaslian, dan elaborasi. Pengumpulan data penelitian menggunakan soal essay dalam mengukur kreativitas matematika siswa. Hasil penelitian menunjukkan bahwa model Brain Based Learning mampu mengembangkan kreativitas yang dimilki siswa dan mendorong sisa untuk memiliki ide dan gagasan yang terbaru dalam menyelesaikan permasalahan dalam proses pembelajaran sesuai dengan pengetahuan yang dimilikinya. Sehingga penelitian ini layak untuk diteliti dan dikembangkan ke tahap penelitian berikutnya.

Kata Kunci: Kreativitas, Pembelajaran Matematika, Brain Based Learning.

\section{Pendahuluan}

Pengembangan kreativitas menjadi hal yang terpenting dalam proses pembelajaran (National Education Association, 2012; Permendikbud, 2016), agar siswa belajar bagaimana menemukan jawaban yang inovatif dan belajar bagaimana melihat suatu pemecahan masalah dari berbagai sudut pandang serta dapat menyelesaikan pemecahan masalah dengan berbagai cara. Kreativitas sebagai kemampuan mencerminkan kelancaran, keluwesan dan orisinalitas berpikir serta kemampuan elaborasi (mengembangkan, memperkaya, memerinci) suatu gagasan. Kreativitas adalah kunci untuk meraih keberhasilan dalam memecahkan masalah. Kreativitaslah yang menjembatani antara tahap pengelolaan kognisi dan tahap eksekusi agar seseorang memeliki prestasi dan hasil yang menyakinkan (Adiansha \& Sumantri, 2017b; Sunito, 2013). Kreativitas merupakan kemampuan untuk menghasilkan sesuatu yang baru dan tepat sehingga mencerminkan wawasan rasa ingin tahu serta dalam kemampuan mengidentifikasi hubungan antara konsep dan gagasan (Adiansha \& Sumantri, 2017a; Adiansha, Sumantri, \& Makmuri, 2018; Christou, 2017).

Kreativitas siswa yang digunakan merupakan fokus pada pembelajaran matematika (Kenedi, 2017; Kusumawardani, 2015), sehingga tujuan dasar dalam pembelajaran metamatika di sekolah dasar yaitu menanamkan keterampilan kuantifikasi serta pengembangan kompetensi dalam memecahkan masalah. Kreativitas siswa dapat diukur melalui kefasihan disandikan oleh jumlah gagasan yang relevan dan tidak berulang yang dihasilkan. Relevansi dinilai berdasarkan kesesuaian respon saat dipertimbangkan dalam kaitannya dengan masalah ujian; Fleksibilitas diwakili oleh kemampuan seseorang untuk menghasilkan gagasan yang berbeda dalam pendekatan atau tren pemikiran. Semua gagasan yang berbeda dalam pendekatan atau tren pemikiran diperlakukan sebagai satu untuk tujuan penilaian fleksibilitas; Orisinalitas diwakili oleh ketidakjelasan respon yang diberikan; dan Elaborasi diwakili oleh kemampuan seseorang untuk menambahkan lebih banyak gagasan.

Salah satu contoh soal dalam mencari kreativitas yang dimiliki siswa yaitu membuat sebanyak-banyaknya gambar dari lingkaran sehingga harus menjadi bagian utama dari gambar yang buat. Gambar lingkaran tersebut 
dengan membuat goresan-goresan di dalam lingkaran, di luar lingkaran, ataupun di dalam serta di luar lingkaran sesuai keinginan dalam membuat gambar serta memberikan judul pada gambar 1 tersebut, sebagai beriukut:

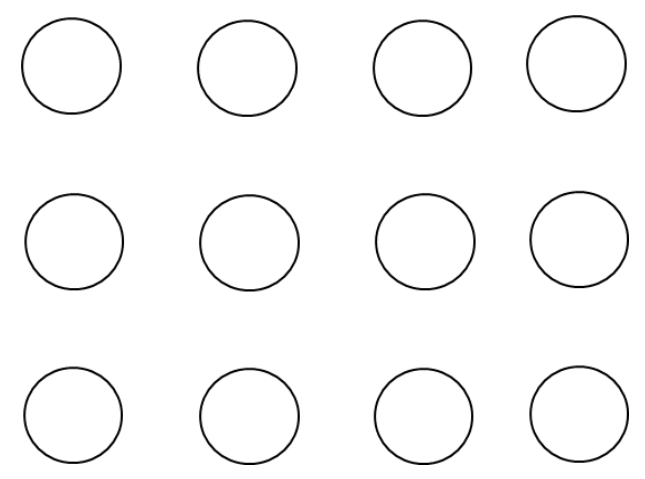

Gambar 1. Tes Kreativitas Siswa

Instrumen tes diberikan kepada siswa untuk bisa mengetahui tingkat kreativitas siswa dalam pembelajaran matematika dapat dilihat sesuai dengan indikator-indikator pada kelancaran, keluwesan, keaslian, dan elaborasi. Sehingga akan ditemukan gejala-gejala terhadap siswa dalam kreativitas yang dimiliki. Melihat pentingnya kreativitas, maka pembelajaran sebagai alternatif yang diterapkan yaitu dengan menggunakan model Brain Based Learning.

Model Brain Based Learning merupakan pembelajaran yang berpusat pada kemapuan otak yang dimiliki siswa dengan memenuhi 12 prinsip utama, yaitu; 1) Pembelajaran melibatkan aspek psikologis; 2) Pikiran bersifat sosial; 3) Mencari sesuatu yang bermakna; 4) Pencarian makna terjadi berdasarkan suatu pola; 5) Emosi sangat berpengaruh terhadap pembuatan pola; 6) Otak memproses sebagian dan keseluruhan informasi secara bersamaan; 7) Belajar melibatkan perhatian dan pandangan yang berpusat pada sekelilingnya; 8) Belajar dilakukan secara sadar dan tak sadar; 9) Terdapat dua pendekatan pada ingatan, yaitu spasial dan prosedural; 10) Belajar itu berkembang; 11) Belajar secara kompleks; 12) Setiap otak adalah organisasi yang unik (Sukoco, 2016; Yulvinamaesari, 2014).

Kebaharuan dalam penelitian ini terjadi ketika siswa mengerjakan intrumen pada gambar 1, sehingga hasil yang diharapkan dalam penelitian ini siswa mampu membuat kreativitasnya atau kemampuan dalam memaksimalkan fungsi otaknya sehingga melahirkan ide dan gagasan yang terbaru. Kemampuan yang setiap dimiliki siswa pasti berbeda-beda sehingga bisa melahirkan kreativitas yang baik.

Berdasarkan uraian di atas, maka diperlukan dalam pengembangan kreativitas yang dimiliki siswa. Sehingga berkeinginan untuk melakukan penelitian dengan judul Pengembangan Kreativitas dalam pembelajaran matematika Melalui Model Brain Based Learning Siswa Sekolah Dasar Negeri Kecamatan Bolo Kabupaten Bima. Sehingga tujuan dalam penelitian ini yaitu untuk mengetahui pengembangan kreativitas dalam pembelajaran matematika melalui model Brain Based Learning pada siswa SD.

\section{Metode}

Tujuan utama dalam penelitian ini adalah untuk mengembangkan kreativitas siswa melalui model Brain Based Learning dalam pembelajaran matematika. Dalam penelitian akan diberikan perlakuan melalui model Brain Based Learning yaitu pada sekolah eksperimen dan diberikan perlakuan melalui model Konversional yaitu pada sekolah kontrol. Penentuan kelompok tersebut dipilih secara acak dan yang menjadi anggota kelompok mempunyai karakteristik yang homogen. Oleh karena itu, model yang paling cocok dalam penelitian ini adalah metode eksperimen murni (Nana Syaodih Sukmadinanta, 2007).

Penelitian ini dilakukan selama satu semester. Pertemuan dalam mengukur kreativitas selama kurun waktu tersebut sangat tepat, mengingat tujuan yang ingin dicapai adalah terjadinya pengembangan kreativitas. Oleh karena itu, model Brain Based Learning ini dapat mencapai sasaran, diupayakan agar proses pembelajarannya berlangsung secara optimal. Dalam setiap pertemuan, peneliti dibantu oleh satu anggota dosen sebagai kolegan dalam penelitian ini. 
Sedangkan populasi dalam penelitian ini adalah siswa SDN Kecamatan Bolo yaitu SDN 1 Sila, SDN 2 Sila, SDN 3 Sila, SDN Inpres Kananga 2, SDN Inpres Kara, SDN Inpres Nggeru, SDN Inpres Palisondo, SDN Inpres Sanolo, SDN Inpres Sondosia, SDN Inpres Tambe, SDN Nggembe, SDN Pali Sila, SDN Rada, dan SDN Inpres Nggembe. Namun, dari masing-masing sekolah tersebut akan dilakukan random sehingga dipilih beberapa sekolah yang akan dijadikan sebagai sampenya diantaranya yaitu SDN Rada dan SDN Nggembe. Penentuan kelasnya akan dipilih kelas $\mathrm{V}$ dari masing-masing sekolah tersebut. Berdasarkan tingkat kualitas dari SDN Rada dan SDN Nggembe memiliki akreditasi sekolah yang sama sehingga kesetaraan terhadap sekolah tersebut dapat dijadikan sebagai subjek dalam penelitian ini. Sehingga ditentukan bahwa kelas Eksperimen yaitu SDN Nggembe dan Kelas Kontrol yaitu SDN Rada.

Untuk mengukur kreativitas siswa digunakan dalam bentuk Soal Esay seperti yang tampak pada bagian latarbelakang masalah yang memuat gambar lingkaran sehingga bentuk soal lingkaran tersebut dapat melihat perkembangan kreativitas siswa. Instrumen penelitian yang digunakan telah dilakukan uji kelayakan terhadap ahli media, ahli bahasa dan ahli psikologi yang telah digunakan saat ujian tesis, sehingga dilanjutkan dalam penelitian ini. Maka kisi-kisi intrumen kreaivitas disesuaikan dalam tabel 2 di bawah ini.

Tabel 2. Kisi-Kisi Instrumen Kreativitas Siswa

\begin{tabular}{cll}
\hline No & Dimensi & \multicolumn{1}{c}{ Indikator } \\
\hline 1 & Kelancaran & Mengemukakan banyak gagasan yang berbeda serta jawaban lebih dari satu. \\
2 & Kelenturan & Menghasilkan gagasan, cara, jawaban yang bervariasi dari sudut pandang yang berbeda \\
3 & Orisinalitas & Menghasilkan ungkapan, ide baru yang unik \\
4 & Elaborasi & $\begin{array}{l}\text { Memperkaya dan mengembangkan suatu gagasan, menambah atau memerinci detail suatu } \\
\text { obyek gagasan menjadi lebih banyak dan jelas. }\end{array}$ \\
\hline
\end{tabular}

Tabel 3. Rubrik Pedoman Penilaian Kreativitas siswa

\begin{tabular}{|c|c|c|c|}
\hline No & Indikator & Aspek yang diukur & Skor \\
\hline \multirow[t]{5}{*}{1} & Kelancaran & Memberikan sebuah ide yang relevan dalam menyelesaikan masalah yang ada & 1 \\
\hline & & Memberikan dua ide yang relevan tetapi pengungkapannya kurang jelan & 2 \\
\hline & & $\begin{array}{l}\text { Memberikan tiga ide yang relevan dengan masalah dan pengungkapan lengkap } \\
\text { serta jelas. }\end{array}$ & 3 \\
\hline & & $\begin{array}{l}\text { Memberikan empat ide yang relevan dan penyelesaian masalah tetapi } \\
\text { pengungkapannya kurang jelas. }\end{array}$ & 4 \\
\hline & & Memberikan lima ide yang relevan dan pengungkapannya lengkap serta jelas & 5 \\
\hline \multirow[t]{5}{*}{2} & Kelenturan & Hanya memberikan satu jawaban & 1 \\
\hline & & $\begin{array}{l}\text { Memberikan dua jawaban hanya dengan satu cara dan terdapat kekeliruan dalam } \\
\text { prosesnya }\end{array}$ & 2 \\
\hline & & Memberikan tiga jawaban dengan satu cara dan benar & 3 \\
\hline & & $\begin{array}{l}\text { Memberikan empat jawaban lebih dari satu cara tetapi hasilnya masih ada } \\
\text { kesalahan }\end{array}$ & 4 \\
\hline & & Memberikan lima jawaban lebih dari satu cara proses dan hasilnya benar. & 5 \\
\hline \multirow[t]{5}{*}{3} & Orisinalitas & Hanya memberikan satu jawaban & 1 \\
\hline & & Memberiakn dua jawaban dengan caranya sendiri tetapi sulit dipahami & 2 \\
\hline & & $\begin{array}{l}\text { Memberiakn tiga jawaban dengan caranya sendiri dapat dipahami tetapi tidak } \\
\text { selesai }\end{array}$ & 3 \\
\hline & & Membikan empat jawaban tetapi tidak selesai & 4 \\
\hline & & Memberikan lima jawaban dan benar & 5 \\
\hline \multirow[t]{5}{*}{4} & Elaborasi & Memberi sebuah jawaban & 1 \\
\hline & & Terdapat kekelliruan dalam memperluas situasi tanpa disertai perincian & 2 \\
\hline & & $\begin{array}{l}\text { Terdapat kekelliruan dalam memperluas situasi dan disertai perincian yang kurang } \\
\text { detai }\end{array}$ & 3 \\
\hline & & Memperluas situasi dengan benar merincinya kurang detail & 4 \\
\hline & & Memperluas situasi dengan benar merincinya dengan detail & 5 \\
\hline
\end{tabular}

\section{Hasil dan Pembahasan}

Penelitian ini menghasilkan data untuk dianalisis berupa data hasil tes pengembangan kreativitas siswa dengan tujuan untuk melihat sejauhmana kemampuan kreativitas siswa terutama pada siswa SD yang ada di Kecamatan Bolo Kabupaten Bima Provinsi Nusa Tenggara Barat. Dalam penelitian telah diberikan perlakuan 
melalui model Brain Based Learning yaitu pada sekolah eksperimen dan telah diberikan perlakuan melalui model Konversional yaitu pada sekolah kontrol. Sekolah Eksperimen dilaksanakan di SDN Nggembe dan Sekolah Kontrol dilaksanakn di SDN Rada, sama-sama pada siswa kelas V (lima). Berdasarkan hasil Uji Deskriptif Kreativitas Siswa dengan menggunaka SPSS Versi 26.0 adalah sebagai berikut:

Tabel 4. Hasil Uji Deskriptif Kreativitas Siswa

\begin{tabular}{|c|c|c|c|c|c|c|c|c|c|}
\hline & $\begin{array}{l}\mathrm{N} \\
\text { Statistic }\end{array}$ & $\begin{array}{l}\text { Range } \\
\text { Statistic }\end{array}$ & $\begin{array}{l}\text { Minimum } \\
\text { Statistic }\end{array}$ & $\begin{array}{l}\text { Maximum } \\
\text { Statistic }\end{array}$ & $\begin{array}{l}\text { Sum } \\
\text { Statistic }\end{array}$ & $\begin{array}{l}\text { Mean } \\
\text { Statistic }\end{array}$ & $\begin{array}{l}\text { Std. } \\
\text { Error }\end{array}$ & $\begin{array}{l}\text { Std. } \\
\text { Deviation } \\
\text { Statistic }\end{array}$ & $\begin{array}{l}\text { Variance } \\
\text { Statistic }\end{array}$ \\
\hline Kelancaran & 46 & 3 & 2 & 5 & 150 & 3.26 & .126 & .855 & .730 \\
\hline Kelenturan & 46 & 3 & 2 & 5 & 150 & 3.26 & .126 & .855 & .730 \\
\hline Orisinalitas & 46 & 3 & 2 & 5 & 147 & 3.20 & .130 & .885 & .783 \\
\hline Elaborasi & 46 & 2 & 2 & 4 & 149 & 3.24 & .129 & .874 & .764 \\
\hline Kreativitas & 46 & 10 & 8 & 18 & 595 & 12.93 & .415 & 2.816 & 7.929 \\
\hline $\begin{array}{r}\text { Valid N } \\
\text { (listwise) }\end{array}$ & 46 & & & & & & & & \\
\hline
\end{tabular}

Tabel 5. Hasil Uji Deskriptif Kreativitas pada jumlah Rata-Rata

\begin{tabular}{|c|c|c|c|c|c|c|c|c|c|}
\hline & $\begin{array}{l}\mathrm{N} \\
\text { Statistic }\end{array}$ & $\begin{array}{l}\text { Range } \\
\text { Statistic }\end{array}$ & $\begin{array}{l}\text { Minimum } \\
\text { Statistic }\end{array}$ & $\begin{array}{l}\text { Maximum } \\
\text { Statistic }\end{array}$ & $\begin{array}{l}\text { Sum } \\
\text { Statistic }\end{array}$ & $\begin{array}{l}\text { Mean } \\
\text { Statistic }\end{array}$ & Std. Error & $\begin{array}{l}\text { Std. } \\
\text { Deviation } \\
\text { Statistic }\end{array}$ & $\begin{array}{l}\text { Variance } \\
\text { Statistic }\end{array}$ \\
\hline SDN_Rada & 23 & 10 & 8 & 18 & 295 & 12.83 & .664 & 3.186 & 10.150 \\
\hline SDN_Nggembe & 23 & 10 & 8 & 18 & 300 & 13.04 & .513 & 2.458 & 6.043 \\
\hline Valid N (listwise) & 23 & & & & & & & & \\
\hline
\end{tabular}

Dari tabel 4 di atas menunjukkan bahwa hasil uji destripsi kreativitas siswa dengan menggunakan Model Brain Based Learning dan Model Konversional dalam mengembangkan kreativitas siswa terlihat bahwa rata-rata sebesar 12.93, standar deviasi sebesar 2.816, nilai maksimum sebesar 18, nilai minimum 18 , dan jumlah statistika dari 46 siswa sebesar 595. Deskripsi data selanjutnya berupa data kreativitas siswa yang disajikan dalam bentuk tabel distribusi frekuensi. Pengolahan data dilakukan dengan manual berbantuan SPSS Versi 26.0 kemudian disusun berdasarkan pembelajaran yang diberikan sebagai berikut.

Berdasarkan tabel 3 menunjukkan bahwa jumlah responden dari SDN Nggembe dan SDN Rada sebanyak 46 dengan nilai 13, 14 dan 15 yang memiliki frekuensi terbanyak yaitu 6, kemudian nilai 10, 11 dan 16 dengan frekuensi 5, nilai 6, 9,12 dan 18 dengan frekuensi 3, nilai 17 dengan frekuensi hanya 1.

Tabel 6. Hasil uji Frekuensi Kreativitas Siswa dengan Menggunakan SPSS

\begin{tabular}{ccr|r|r|r}
\hline & Frequency & Percent & Valid Percent & Cumulative Percent \\
\hline Valid & 1 & 3 & 6.5 & 6.5 & 6.5 \\
& 2 & 3 & 6.5 & 6.5 & 13.0 \\
& 3 & 5 & 10.9 & 10.9 & 23.9 \\
4 & 5 & 10.9 & 10.9 & 34.8 \\
5 & 3 & 6.5 & 6.5 & 41.3 \\
6 & 6 & 13.0 & 13.0 & 54.3 \\
7 & 6 & 13.0 & 13.0 & 67.4 \\
8 & 6 & 13.0 & 13.0 & 80.4 \\
9 & 5 & 10.9 & 10.9 & 91.3 \\
10 & 1 & 2.2 & 2.2 & 93.5 \\
11 & 3 & 6.5 & 6.5 & 100.0 \\
\hline & 46 & 100.0 & 100.0 & \\
\hline
\end{tabular}

Pengumpulan data kreativitas siswa merupakan menganalisis data dengan tujuan untuk membuktikan hipotesis penelitian. Sebelum dilakukan uji analisis tersebut, terlebih dahulu dilakukan pengujian prasarat analisis yang meliputi uji normalitas dan uji homogenitas. Tujuan dari uji normalitas adalah untuk adalah untuk melihat apakah data yang diambil berasal dari sampel yang berdistribusi normal atau tidak. Uji homogenitas bertujuan untuk melihat apakah data yang diambil memiliki varians yang homogen atau tidak. Uji prasarat 
dilakukan dilakukan dengan menggunakan Software SPSS V.26 dengan taraf signifikansi 0.05. Data dikatakan berdistribusi normal dan homogen jika nilai signifikansi hasil ujian prasyarat $>0.05$.

\section{Uji Normalitas}

Uji normalitas pada model regresi dilakukan untuk menguji apakah nilai residual terdistribusi secara normal atau tidak. Model regresi yang baik adalah dengan melihat nilai residual yang terdistribusi secara normal. Cara uji normalitas adalah dengan metode uji one simple kolmogorov smirnov. Kriteria pengujiannya adalah sebagai berikut:

- Jika nilai signifikasi $>0,05$, maka data berdistribusi normal.

- Jika nilai signifikasi <0,05, maka data tidak berdistribusi normal

Tabel 7. Hasil Uji Normalitas Data Kreativitas Siswa

\begin{tabular}{|c|c|c|c|c|c|c|c|c|}
\hline \multirow[b]{3}{*}{ Kreativitas } & \multirow[b]{2}{*}{$\underline{\text { Sekolah }}$} & \multicolumn{3}{|c|}{ Kolmogorov-Smirnov ${ }^{\mathrm{a}}$} & \multicolumn{4}{|l|}{ Shapiro-Wilk } \\
\hline & & Statistic & df & Sig. & Statistic & df & Sig. & \\
\hline & SDN Nggembe & .173 & 23 & .072 & .960 & 23 & & .465 \\
\hline & SDN Rada & .117 & 23 & $.200^{*}$ & .944 & 23 & & .217 \\
\hline
\end{tabular}

*. This is a lower bound of the true significance.

a. Lilliefors Significance Correction

Berdasarkah hasil output SPSS 26.0 pada tabel Test of Normality di atas, diperoleh nilai Shapiro-Wilk Sig. untuk data di SDN Nggembe adalah sebesar 0,465, dan SDN 1 Rada sebesar 0,217. Berdasarkan dasar pengambilan keputusan dalam uji normalitas di atas, maka data diseluruh SDN tersebut, baik SDN Nggembe dan SDN Rada adalah > 0,05. Dengan demikian dapat disimpulkan bahwa data di SDN Kecamatan Bolo adalah berdistribusi normal.

\section{Uji Homogenitas}

Dalam analisis statistik, uji homogenitas bertujuan untuk mengetahui apakah variasi beberapa data dari populasi memiliki varians yang sama atau tidak. Uji ini umumnya berfungsi sebagai syarat (walaupun bukan merupakan syarat mutlak) dalam analisis komparatif. Asumsi yang mendasari dalam Analisis of varians (ANOVA) yaitu bahwa varians dari beberapa populasi adalah sama atau homogen. Homogenitas bukan merupakan syarat mutlak artinya walaupun varians data tidak sama atau tidak homogen, uji independent sample $\mathrm{t}$ test masih tetap dapat dilakukan untuk menganalisis data penelitian, akan tetapi pengambilan keputusan mengacu pada hasil equal variance not assumed. Uji homogenitas digunakan sebagai bahan acuan untuk menentukan keputusan uji statistik berikutnya. Dasar atau pedoman pengambilan keputusan dalam uji homogenitas adalah sebagai berikut:

a. Jika nilai signifikansi atau Sig. < 0,05, maka dikatakan bahwa varians dari dua atau lebih kelompok populasi data adalah tidak sama (tidak homogen).

b. Jika nilai signifikansi atau Sig. > 0,05, maka dikatakan bahwa varians dari dua atau lebih kelompok populasi data adalah sama (homogen).

Hasil uji homogenitas pada data kreativitas siswa di SDN Kecamatan Bolo pada SDN Rada, SDN Nggembe dan SDN 1 Sila dapat dilihat pada Tabel 8. Berdasarkan tabel output "Test of Homogeneity of Variances" di atas diketahui nilai signifikansi (Sig.) variabel kreativitas siswa pada siswa SDN Nggembe dan SDN Rada adalah sebesar 0,194. Karena nilai Sig. 0,194<0,05, maka sebagaimana dasar pengambilan keputusan dalam uji homogenitas di atas, dapat disimpulkan bahwa varians data kreativitas siswa pada SDN di Kecamatan Bolo adalah homogen.

Tabel 8. Uji Homogenitas Kreativitas Siswa

\begin{tabular}{llr|r|r|r}
\hline & Levene Statistic & df1 & df2 & \multicolumn{2}{l}{ Sig. } \\
\hline Kreativitas & Based on Mean & 1.740 & 1 & 44 & .194 \\
& Based on Median & 1.448 & 1 & 44 & .235 \\
& $\begin{array}{l}\text { Based on Median and } \\
\text { with adjusted df }\end{array}$ & 1.448 & 1 & 43.921 & .235 \\
Based on trimmed mean & & & & \\
\hline
\end{tabular}




\section{Pengujian Hipotesis}

Secara umum penelitian ini bertujuan untuk melihat pengembangan kreativitas siswa pada pembelajaran matematika melalui model Brain Based Learning. Dan model konversional. Berdasarkan rumusan masalah penelitian, maka disusunlah hipotesis yang berupa dugaan sementara dari hasil penelitian yang masih harus diuji lagi kebenarannya. Untuk menguji hipotesis haruslah dilakukan uji prasyarat, yang telah dilaksanakan dan hasilnya memperbolehkan untuk dilakukan uji analisis untuk menguji hipotesis. Uji prasyarat telah dilakukan sebelumnya dan menyatakan bahwa layak untuk dilakukan uji analisis pada sampel tersebut. Pengujian hipotesis dilakukan menggunakan uji One Sample T-Test dengan bantuan software SPSS V.26, pada taraf signifikan 0.05.

Hasil Uji One Sample T-Test Dalam konteks penelitian pada umumnya digunakan untuk membandingkan rata-rata sampel yang diteliti dengan rata-rata populasi yang sudah ada. Selain itu, uji one sample $\mathrm{t}$ test dapat juga dipakai untuk menguji hipotesis dalam statistik deskripsif jika data penelitian berskala interval atau rasio. Uji ini digunakan untuk mengetahui perbedaan nilai rata-rata populasi yang digunakan sebagai pembanding dengan rata-rata sebuah sampel. Dari hasi uji ini akan diketahui apakah rata-rata populasi yang digunakan sebagai pembanding berbeda secara signifikan dengan rata-rata sebuah sampel, jika ada perbedaan, rata-rata manakah yang lebih tinggi.

Berdasarkan tabel One-Sample Test pada tabel 9 di di bawah ini, diketahui nilai t ( $\mathrm{t}$ hitung) adalah sebesar 31.155. Nilai df (degree of freedom) atau derajad kebebasan adalah sebesar 45. Nilai Sig. (2-tailed) atau nilai signifikansi dengan uji dua sisi adalah sebesar 0,000. Dasar pengambilan keputusan yaitu jika nilai sig. (2itailed) $<0,05$, maka Ho ditolak dan jika nilai sig. (2itailed) $>0,05$, maka Ho diterima. Maka diketahui nilai thitung sebesar 31.155. Dalam ketentuan mencari t tabel (uji dua sisi; $d f)=(0.025 ; 45)$ kemudian pada distribusi nilait tabel statistika, maka diteukan nilai $\mathrm{t}$ tabel sebesar 2.01410. Karena nilai $\mathrm{t}$ hitung sebesar $31.155>\mathrm{t}$ tabel 2.01410, maka $\mathrm{H}_{0}$ ditolak dan Ha diterima. Sehingga dapat disimpulakan bawha nilai rata-rata kreativitas siswa tidak sama.

Tabel 9. One-Sampel Test Kreativitas Siswa SDN Kecamatan Bolo

\begin{tabular}{|c|c|c|c|c|c|}
\hline & Test Val & lue $=0$ & & & \\
\hline & & & & & 95\% Confidence Interval of the Difference \\
\hline & $\mathrm{t}$ & df & Sig. (2-tailed) & Mean Difference & Lower $\quad$ Upper \\
\hline Kreativitas & 31.155 & 45 & .000 & 12.935 & 12.10 \\
\hline
\end{tabular}

Berdasakan hasil uji data kreativitas pada siswa sekolah dasar di Kecamatan Bolo dengan menggunakan Model Brain Based Learning menunjukkan bahwa hasil analisis nilai kreativitas yang dimiliki siswa baik dibandingkan dengan model pembelajaran konversional. Pengembangan terhadap kreativitas sangat penting dalam meningkatkan mutu pembelajaran Sekolah Dasar di Indonesia (Adiansha et al., 2018; Kupers, LehmannWermser, McPherson, \& Geert, 2019; Oktavia, 2014), karena pembelajaran dapat meningkatkan kemampuan siswa lewat kemampuan dalam memaksimalkan fungsi otak sehingga menghasilkan pembelajaran dengan cara berpikir, ide dan gagasan yang baru.

Pada pengembangan kreativitas siswa ditentukan oleh bagaimana guru di sekolah mampu memggunakan model pembelajaran yang menstimulus siswa untuk memaksimalkan fungsi otakya secara aktif. Model pembelajaran yang sesuai untuk menumbuhkan fungsi otak siswa dalam proses pembelajaran yaitu model Brain Based Learning. Model Brain Based Learning merupakan pembelajaran yang dapat meningkatkan kemampuan yang dimiliki siswa lewat kemampuan dalam memaksimalkan fungsi otak yang dimilikinya sehingga menghasilkan pembelajaran dengan cara berpikir, ide dan gagasan yang baru (Adiansha et al., 2018; Ningsih, 2017; Waree, 2017).

Berdasarkan hasil penelitian dan perhitungan secara statistik dengan menggunakan uji-t pada $\alpha=0,05$ diperoleh harga thitung sebesar 31.155 lebih besar dari ttabel sebesar 2.01410. Hal ini menunjukkan bahwa hipotesis nol ( $\mathrm{HO})$ ditolak dan hipotesis kerja $(\mathrm{Ha})$ diterima. Dengan ditolaknya $\mathrm{HO}$ dari hasil pengujian hipotesis, maka dapat disimpulkan bahwa terdapat pengembangan yang signifikan tentang kreativitas siswa dengan menggunakan model Brain Based Learning.

Pada perbedaan pengembangan kreativitas yang dimiliki siswa dengan menggunakan model Brain Based Learning pada SDN Nggembe memiliki nilai rata-rata sebesar 13.04 lebih tinggi dari pada pengembangan 
kreativitas yang dimiliki siswa dengan menggunakan model pembelajaran konversional pada SDN Rada yang memilki nilai rata-rata sebesar 12.83. Hal tersebut menunjukkan bahwa model Brain Based Learning mampu mengembangkan kreativitas yang dimilki siswa dan mendorong sisa untuk memiliki ide dan gagasan yang terbaru dalam menyelesaikan permasalahan dalam proses pembelajaran sesuai dengan pengetahuan yang dimilikinya.

Pada proses pembelajaran dengan menggunakan model Brain Based Learning, dimana guru mengaktifkan pengetahuan yang sudah dimiliki siswa melalui pemanfaatan fungsi otak yang dimiliki siswa, kemudian guru memberi kesempatan kepada siswa untuk untuk menuangkan ide dan gagasan yang dimilikin kemudian disimpulkan bersama-sama oleh siswa dan guru, sehingga tercipta lingkungan belajar yang aktif dan kondusif, serta evaluasi terjadi selama proses pembelajaran berlangsung. Dengan demikian pengembangan kreativitas yang dimiliki siswa dapat meningkat.

\section{Simpulan}

Berdasarkan hasil temuan di atas menunjukkan bahwa Pada perbedaan pengembangan kreativitas yang dimiliki siswa dengan menggunakan model Brain Based Learning pada SDN Nggembe memiliki nilai rata-rata sebesar 13.04 lebih tinggi dari pada pengembangan kreativitas yang dimiliki siswa dengan menggunakan model pembelajaran konversional pada SDN Rada yang memilki nilai rata-rata sebesar 12.83. Hal tersebut menunjukkan bahwa Model Brain Based Learning mampu mengembangkan kreativitas yang dimilki siswa dan mendorong sisa untuk memiliki ide dan gagasan yang terbaru dalam menyelesaikan permasalahan dalam proses pembelajaran sesuai dengan pengetahuan yang dimilikinya

\section{Ucapan Terima Kasih}

Peneliti mengucapkan terima kasih kepada Kemenristekdikti/BRIN dalam rangka pemberian hibah Penelitian Dosen Pemula dan STKIP Taman Siswa Bima sehingga penelitian ini dapat terlaksana.

\section{Daftar Pustaka}

Adiansha, A. A., \& Sumantri, M. S. (2017a). The Effect of Brain Based Learning Model and Creative Thinking about the Ability of Mathematics Concept of Elementary Students. 5(12), 1195-1199. https://doi.org/10.12691/education-5-12-4

Adiansha, A. A., \& Sumantri, M. S. (2017b). The Effect of Brain Based Learning Model and Creative Thinking on the Ability of Mathematics Concept of Elementary Students. American Journal of Educational Research, 5(12), 1195-1199. https://doi.org/10.12691/education-5-12-4

Adiansha, A. A., Sumantri, M. S., \& Makmuri, M. (2018). Pengaruh model Brain Based Learning terhadap kemampuan komunikasi matematis siswa ditinjau dari kreativitas. Premiere Educandum : Jurnal Pendidikan Dasar Dan Pembelajaran, 8(2), 127. https://doi.org/10.25273/pe.v8i2.2905

Christou, C. (2017). Creativity And Imagination In Mathematics. Proceedings Mathematical Creativity and Giftedness: University of Cyprus, Nicosia, Cyprus.

Kenedi. (2017). Pengembangan Kreativitas Siswa dalam Proses Pembelajaran di Kelas II SMP Nergeri 3 Rokan IV Koto. Jurnal Ilmu Pendidikan Sosial, Sains, Dan Humaniora, 3(2), 329-348.

Kupers, E., Lehmann-Wermser, A., McPherson, G., \& Geert, P. van. (2019). Children's Creativity: A Theoretical Framework and Systematic Review. Review of Educational Research, 89(1), 93-124. https://doi.org/10.3102/0034654318815707

Kusumawardani, R. (2015). Peningkatan Kreativitas melalui Pendekatan Brain Based Learning. Jurnal Pendidikan Usia Dini, 9(1), 143-162. https://doi.org/10.21009/JPUD.091.09

Nana Syaodih Sukmadinanta. (2007). Metode Penelitian Pendididikan. Remaja Rosdakarya. (Cetakan ketiga).

National Education Association. (2012). An educators guide to the "fours cs. United State.

Ningsih, M. M. and Y. P. (2017). The Effects of Brain Based Learning Approach on Motivation and Students Achievement in Mathematics Learning. Journal of Physics: Conference Series, 895(1), 12057. Retrieved from http://stacks.iop.org/1742-6596/895/i=1/a=012057

Oktavia, Y. (2014). Usaha Kepala Sekolah dalam Meningkatkan Kreativitas Guru dalam Pembelajaran di Sekolah Dasar. Jurnal Administrasi Pendidikan, 2(1), 808-831. https://doi.org/DOI : https://doi.org/10.23036/bmp.v2i1.3828

Permendikbud. (2016). Permendikbud Th. 2016 No. 021 Ttg. Standar Isi Pend. Dasar_Menengah.pdf.

Sukoco, H. \& A. M. (2016). Pengaruh Pendekatan Brain Based Learning terhadap Kemampuan Komunikasi Matematis dan Self-Efficacy Siswa SMA. Pythagoras Jurnal Pendidikan Matematika.

Sunito, I. (2013). Metaphorming Beberapa Strategi Berpikir Kreatif. Jakarta: Indeks. 
Waree, C. (2017). An Increasing of Primary School Teachers? Competency in Brain-Based Learning. International Education Studies, 10(3), 176. https://doi.org/10.5539/ies.v10n3p176

Yulvinamaesari. (2014). Implementasi Brain Based Learning Dalam Pembelajaran. Prosiding Seminar Nasional, 01, $100-102$. 